\title{
Who Makes the Diagnosis and Implement Treatment for Pelvic Congestion Syndrome
}

\author{
Muhammad Assem Kubtan* and Muhammad Turki Al Abd \\ Department of Surgery, Syrian Private University, Syria
}

Received: February 18, 2019; Published: March 11, 2019

*Corresponding author: Muhammad Assem Kubtan, Department of Surgery, Syrian Private University, Syria

\begin{abstract}
It is well known that chronic pelvic pain (CPP) in women, commonly affects young and childbearing women in various clinical status. Approximately one third of all women commonly suffer with lower abdominal pain and they represent at least $20 \%$ of those attending outpatient gynecology appointments [1]. Frankly this complaint usually is solvable when the real diagnosis has been made, to reach this destination it is appropriate to have a collaboration between more than one specialty, and also to have all diagnostic facilities for making up the diagnosis and implementing the proper treatment.
\end{abstract}

Objectives: Our aim in this study was to find out the incidence of the diagnosis of Pelvic Congestion Syndrome in the Syrian Society, and the implemented treatment.

Material and Methods: We conducted a retrospective study looking for women admitted to a central major hospital (Al Zehrawie Obstetric and Gynecological Diseases Hospital ZOGDH) in Damascus, Syria. Between 2017-2018 there was a 1371 admission to hospital 100\%, from those being admitted, only 164 patients admitted $14 \%$ with a complaint of abdominal pain whom they were presumably subjected to clinical study and management, and the rest were normal delivery and other irrelevant diagnosis.

Results: To our surprise there was not a single case being diagnosed as PCS. Even though there were many cases subjected to Hysterectomy with no confirmed diagnosis clinically or histologically, and we failed to lay our hand on any investigation related to the diagnosis of PCS.

Conclusion: We consider that failure in making the diagnosis of PCS, does not abandon the disease presence in the community. All necessary tools required for making the diagnosis should be made available, a real collaboration should be implemented between various specialties, namely Gynecology, Vascular Surgery, and Interventional Radiology.

We live globally in a little village and no one can claim the entire knowledge in everything.

Keywords: Chronic pelvic pain; Pelvic congestion syndrome; Transcatheter embolization; Ovarian vein insufficiency; Ligation of ovarian vein; Laparoscopic blockage of ovarian vein

\section{Introduction}

Women all over the glob share a similar complaint i.e. chronic pelvic pain (CPP), in low income and in under developed countries women still suffer more than those belonging to Northern Countries due to, lack of advanced diagnostic facilities , due to ill collaboration between related specialties and due to invisibility of related experience in medical health profession. (CPP) has been defined as non-menstrual lower abdominal pain lasting for more than six months duration [1,2]. Those are affected represent almost $15 \%$ of women whom usually suffer from CPP due to various reasons with various predisposing factors, commonly affected women range between the ages 18-50 years old. Women suffering with CPP usually attend Gynecological Clinics seeking for a relief of this agonizing complaint and this represent almost $10-40 \%$ of all attending outpatients' gynecological clinics in USA. In USA it is reported that $35 \%$ of Laparoscopic interventions and $15 \%$ of Hysterectomies have been implemented due to CPP [2-5].

\section{Material and Method}

In this research, our target was to find out the possible incidence of women admitted with lower abdominal pain or CPP within a one year duration, and the incidence of diagnosing Pelvic Congestion Syndrome CPS.

To achieve the answer, we planned to make a retrospective research on women admitted to a major Obstetric Gynecological Hospital (ZOGDH) serving a large heavily populated area in 
Damascus, Syria. This is a hospital receiving mainly full term pregnant women for normal or cesarean surgery delivery, and partially receive patients with gynecological complaint, and CPP. During the six months ended in 2018, there has been 1371 admission, and only 164 women 14\% with an abdominal pain complaint. Those presumably were subjected to the investigations to find the predisposing factor to this complaint. (Table 1) From this review we can be sure that related symptoms during history taken was not properly asked for. Accordingly, any following management can't be regarded as the procedures of choice [6-8].

Table 1: No of patients related to PCS symptoms out of 164 patients.

\begin{tabular}{|c|c|c|c|}
\hline Symptoms & $\begin{array}{c}\text { Number of } \\
\text { patients }\end{array}$ & Percentage & Duration \\
\hline Abdo pain & 49 & $29.87 \%$ & - \\
\hline $\begin{array}{c}\text { Lower abdo } \\
\text { pain }\end{array}$ & 43 & $26.21 \%$ & - \\
\hline Pelvic pain & 3 & $1.82 \%$ & - \\
\hline $\begin{array}{c}\text { Lower abdo } \\
\text { heaviness }\end{array}$ & 14 & $8.53 \%$ & - \\
\hline Low back pain & 29 & $17.68 \%$ & - \\
\hline Dysmenorrhea & 20 & $12.19 \%$ & - \\
\hline Painful Coitus & 1 & $0.60 \%$ & - \\
\hline $\begin{array}{c}\text { Post Coitus } \\
\text { pain }\end{array}$ & - & - & - \\
\hline $\begin{array}{c}\text { Post Coitus } \\
\text { Bleeding }\end{array}$ & 5 & $3.40 \%$ & - \\
\hline Labial Swelling & 1 & $0.60 \%$ & - \\
\hline Sexual agitation & - & - & - \\
\hline
\end{tabular}

\section{Management of PCS}

i. Venous embolization i.e. inserting a venous catheter rail road on a guide wire through the common femoral vein in a retro grad manner into the inferior vena cava reaching anatomically the site of left renal vein and down through the left ovarian vein then injecting an emblazing beads to produce a venous thrombosis, the second way is inject one of the sclerosing agents also to create local thrombosis on the same principle of varicose veins sclerotherapy.

ii. Laparoscopic interference, finding the dilated left ovarian vein and blocking it by tantalum clips.

iii. The classical way of exploring the left side of retro peritoneal space in conventional surgery and ligate the left ovarian vein.

\section{Discussion}

In the advanced communities i.e. in those of western societies, since there is an excellent collaboration between various specialties on equal footing, all facilities of investigation and clinical experience are implemented within reach to make up the diagnosis and implement the proper management to combat this dilemma, needless to mention that adequate fruitful and ethical collaboration between various branches of medical specialties usually implemented. It is acceptable that women suffering with CPP usually attend Gynecological Clinics seeking for a relief of this agonizing complaint and this represent almost $10-40 \%$ of all attending outpatients' gynecological clinics in USA. In USA it is reported that $35 \%$ of Laparoscopic interventions and $15 \%$ of Hysterectomies have been implemented due to CPP [9$12]$.

Despite the number of the women admitted with this complaint we failed to find a single case being admitted were the diagnosis was PCS. Since the specialist in Gynecology are variably are short of comprehending the knowledge of investigating vascular related complaint in women and despite the fact that almost all of them are well trained in using ultrasound system related to obstetrics and gynecology specialty, there is a doubt that they have the same standard of experience in using Echo Color Doppler for vascular means, also it is doubted that such hospitals are equipped with CT malty slice for vascular investigation $[13,14]$. This problem embarks its effects on the management of CPP in female patients attending the gynecological clinics or even in obstetric \& gynecological specialized hospitals in the underdeveloped countries, since the workload on hospital personnel is tremendous, and health professionals are always pressurized to make a provisional diagnosis and dealing with symptoms rather than diseases, with the era of developing advanced investigations in the vascular diseases and the establishment of a vascular specialty it became mandatory that always there is an areas of collaboration between various specialties, eventually for the benefit of the patient (Figure 1).

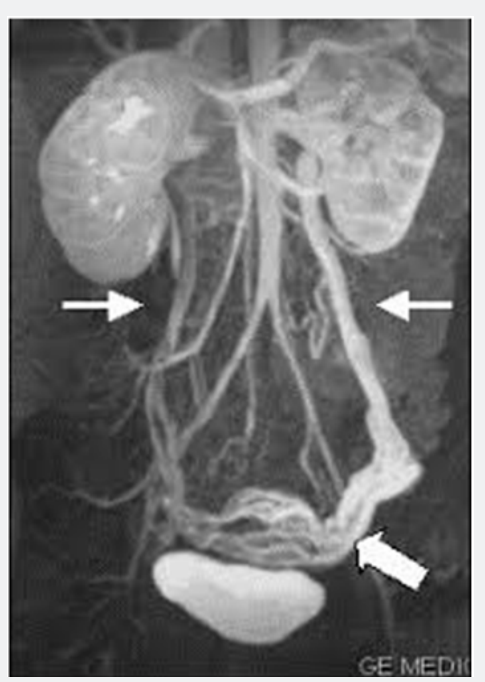

Figure 1 : PCS Characterized by dilated variceal pelvic plexus and dilated Lt Ovarian vein.

Pelvic Congestion Syndrome PCS is one of those areas were gynecologists should include PCS in their differential diagnostic 
list as a an important cause for all those women whom they attend their clinics complaining of lower abdominal pain and CPP, complaints of PCS in women variously present with vague symptoms, heavy menstrual bleeding, agonizing coitus and post coitus sever pain, and in some cases an association with vulvar varices, or lower limbs varicosities, those finding should alert the gynecologist dealing with such patient to the possibility of presence of PCS.

When it come to this status unless the gynecologists are aware of the diagnosis of PCS and how making the diagnosis, it is mandatory to seek support from other specialist i.e. vascular consultation. Now we can stress that there is various tools within hand available to the vascular specialist, starting with clinical vascular experiences, non-invasive investigations such as Colored Echo Doppler which provide a valuable information concerning the Venous flow within the pelvis, the competency of the pelvic venous valves, enlarged diameter of the ovarian and pelvic veins as well as the presence of a retrograde flow in the ovarian veins due to venous valves incompetence, obviously we have to mention anatomically the differences between the right and left ovarian venous drainage proximally were the right ovarian vein drains to the inferior vena cava directly without any effect of hormonal or mechanical pressure from without, while the left ovarian vein drain its blood to the left renal vein in a right angle manner, also its connection with the left renal vein is facing directly the orifice of the suprarenal vein draining the supra renal gland which is loaded with vaso constricting physiological hormones produced by the adrenal medulla, secondly and anatomically speaking the left renal vein commonly passing transversely anterior to abdominal aorta as it makes its way to drain in to the inferior vena cava and posterior to superior mesenteric artery, and sometime it is pressurized by the abdominal aorta being pushed anteriorly, and sometime it is pressurized by the superior mesenteric artery and posteriorly by the anterior wall of the abdominal aorta (Nut Cracker Syndrome ) all those mentioned effects may pave the way to the establishment of PCS [15-21].

Whatever the case is the management of such diagnosis is usually simple to the experienced vascular surgeon, which is characterized by more than one technical approach. Frankly it is unfair that women should suffer chronically from PCS, due to delaying in making the diagnosis, for various reasons whether due to the lack of experience or due to short of equipment's. It should be kept in mind that diagnosis pf PCS depends on knowledge primarily, clinical experience, availability of diagnostic system Colored Echo Doppler, Venography or CT Venous multi slices. We must admit that many clinical problems can't be dealt with by one specialty and requires multi discipline to be involve so reaching the best for the patient. Presumably this is our case in underdeveloped countries where there is a lack of collaboration for the benefit of the patients [21-27].

\section{Conclusion}

We consider that failure to confirm the diagnosis of PCS, does not abandon the PCS diagnosis, but probably due to the shortage of related facilities necessary to making this important and bothering syndrome, secondly probably due to lack of collaboration with experienced Radiologist able to perform necessary investigation such as colored Echo Doppler, Pelvic Venography, or Malty Slice Computed Venography. Vascular Surgeons usually well orientated with conventional and interventional venous procedures for dealing with PCS.

\section{References}

1. Phillips D, Deipolyi AR, Hesketh RL (2014) Pelvic congestion syndrome: etiology of pain, diagnosis, and clinical management. J Vasc Interv Radiol 25(5): 725-733.

2. Shelkey J, Huang C, Karpa K (2014) Case report: pelvic congestion syndrome as an unusual etiology for chronic hip pain in 2 active middle- age women. Sports Health 6(2): 145-148.

3. Farquhar CM, Rogers V, Franks S (1989) A randomized controlled trial of medroxyprogesterone acetate and psychotherapy for the treatment of pelvic congestion. Br J Obstet Gynaecol 96(10): 1153-1162.

4. Nicholson T, Basile A (2006) Pelvic congestion syndrome, who should we treat and how? Tech Vasc Interv Radiol 9(1): 19-23.

5. Ahmed K, Sampath R, Khan MS (2006) Current trends in the diagnosis and management of renal nutcracker syndrome: a review. Eur J Vasc Endovasc Surg 31(4): 410-416.

6. Cheong Y, Stones WR (2006) Chronic pelvic pain: aetiology and therapy. Best Pract Res Clin Obstet Gynaecol 20(5): 695-711.

7. Sichlau MJ, Yao JS, Vogelzang RL (1994) Transcatheterembolo therapy for the treatment of pelvic congestion syndrome. Obstet Gyneco 83: 892-896.

8. Kim HS, Malhotra AD, Rowe PC (2006) Embolotherapy for pelvic congestion syndrome: long-term results. J Vasc Interv Radiol 17(2 Pt 1): $289-297$

9. Abd MTAI, Kubtan MA (2016) Pelvic congestion syndrome, treatment choices. MOJ Surg 3(4): 105-106.

10. Moore, Keith L, Arthur F (1999) Dalley. Clinically Oriented Anatomy. Lippincott Williams \& Wilkins: Philadelphia, Pennsylvania.

11. Mohamed Waseem Osman, Ilias Nikolopoulos, Kannamannadiar Jayaprakasan, Nicholas Raine-Fenning (2013) Pelvic congestion syndrome. Semin Intervent Radiol. 15: 151-157.

12. Ignacio, Elizabeth A (2008) Pelvic congestion syndrome: diagnosis and treatment. Semin Intervent Radiol. 25(4): 361-368.

13. Raffetto JD, Khalil RA (2008) Mechanisms of varicose vein formation: valve dysfunction and wall dilation. Phlebology 23: 85-98.

14. Greiner M, Dadon M, Lemasle P, Cluzel P (2012) How does the pathophysiology influence the treatment of pelvic congestion syndrome and is the result long-lasting? Phlebology 27(Suppl 1): 58-64.

15. Farquhar CM, Rogers V, Franks S (1989) A randomized controlled trial of medroxyprogesterone acetate and psychotherapy for the treatment of pelvic congestion. Br J Obstet Gynaecol 96: 1153-1162.

16. Asciutto G, Mumme A, Asciutto KC, Geier B (2010) Oestradiol levels in varicose vein blood of patients with and without pelvic vein incompetence (PVI): diagnostic implications. Eur J Vasc Endovasc Surg 40: 117121. 
17. Nanavati R, Jasinski P, Adrahtas D, Gasparis A, Labropoulos N (2017) Correlation between pelvic congestion syndrome and body mass index.

18. Rozenblit AM, Ricci ZJ, Tuvia J, Amis ES Jr (2001) Incompetent and dilated ovarian veins: a common CT finding in asymptomatic parous women. AJR Am J Roentgenol 176: 119-122.

19. Hauge M, Gundersen J (1969) Genetics of varicose veins of the lower extremities. Hum Hered 19: 573-580.

20. Matousek V, Prerovsky I (1974) A contribution to the problem of the inheritance of primary varicose veins. Hum Hered 24: 225-235.

21. Brice G, Mansour S, Bell R (2002) Analysis of the phenotypic abnormalities in lymphoedema-distichiasis syndrome in 74 patients with FOXC2 mutations or linkage to 16q24. J Med Genet 39: 478-483.

22. Ignacio EA, Dua R, Sarin S (2008) Pelvic congestion syndrome: diagnosis and treatment. Semin Intervent Radiol 25: 361-368.
23. Ganeshan A, Upponi S, Hon LQ (2007) Chronic pelvic pain due to pelvic congestion syndrome: the role of diagnostic and interventional radiology. Cardiovasc Intervent Radiol 30: 1105-1111.

24. Kwon SH, Oh JH, Ko KR, Park HC, Huh JY (2007) Transcatheter ovarian vein embolization using coils for the treatment of pelvic congestion syndrome. Cardiovasc Intervent Radiol 30: 655-666.

25. Laborda A, Medrano J, de Blas I (2013) Endovascular treatment of pelvic congestion syndrome: visual analog scale (VAS) long-term follow-up clinical evaluation in 202 patients. Cardiovasc Intervent Radiol 36: 1006-1014.

26. Monedero JL, Ezpeleta SZ, Perrin M (2012) Pelvic congestion syndrome can be treated operatively with good long-term results. Phlebology 27 : 65-73.

27. Perry CP (2001) Current concepts of pelvic congestion and chronic pelvic pain JSLS 5(2): 105-110.

\section{Your next submission with Juniper Publishers will reach you the below assets}

- Quality Editorial service

- Swift Peer Review

- Reprints availability

- E-prints Service

- Manuscript Podcast for convenient understanding

- Global attainment for your research

- Manuscript accessibility in different formats

( Pdf, E-pub, Full Text, Audio)

- Unceasing customer service

Track the below URL for one-step submission https://juniperpublishers.com/online-submission.php 